\title{
Stalking of Healthcare Professionals by Their Clients: The Prevalence, Motivation, and Effect
}

\author{
Sefa Bulut, Ali Cissy Usman, Thseen Nazir \\ Guidance and Counseling Psychology Department, Ibn Haldun University, Istanbul, Turkey \\ Email: sefa.bulut@ihu.edu.tr
}

How to cite this paper: Bulut, S., Usman, A.C. and Nazir, T. (2021) Stalking of Healthcare Professionals by Their Clients: The Prevalence, Motivation, and Effect. Open Journal of Medical Psychology, 10, 27-35. https://doi.org/10.4236/ojmp.2021.102003

Received: February 1, 2021

Accepted: April 3, 2021

Published: April 6, 2021

Copyright $\odot 2021$ by author(s) and Scientific Research Publishing Inc. This work is licensed under the Creative Commons Attribution International License (CC BY 4.0).

http://creativecommons.org/licenses/by/4.0/ (c) (i) Open Access

\begin{abstract}
It is proposed that healthcare professionals are prone to be stalked by their patients, but many feel ashamed to talk about it, believing that they might have done something to warrant the stalking. We undertook a rigorous review of the literature with the primitive goal of highlighting noteworthy issues on the stalking of healthcare professionals and psychologists by their patients. Databases such as PubMed and Google Scholar were searched to collate articles and studies on the topic with the keywords "stalker, stalking, assaults, aggression, and physicians". From the review, the prevalence rate of stalking healthcare professionals ranged between $6 \%-53 \%$. This huge variation was largely due to the inconsistencies in the definition of what constituted stalking. The common motives of stalkers were largely due to erotomania or misguided expectation and a sense of resentment due to service dissatisfaction. Finally, it was apparently right to conclude that, medical doctors or healthcare professionals are at risk of being stalked on the grounds of service dissatisfaction, and mismanagement of treatment processes resulting in physical or perceived client injuries. Whereas psychologists and other psychiatrists are more prone to be stalked due to erotomaniac reasons.
\end{abstract}

\section{Keywords}

Stalking, Erotomania, Misguided Expectation, Resentment, Healthcare Professionals

\section{Introduction}

The services provided by healthcare professionals and psychologists could spearhead the development of disheartened notions in a diverse number of people with whom they work with. Some might expect them to tender loving care and attention to the relationship they share with them, while others might 
completely perceive and interpret the attention, sympathy, and empathy of these professional individuals as romantic gestures and interest [1]. Therefore, failure to replicate or meet these demands and expectations could trigger a variety of reactions, including frustration, rage, anger, resentment, attack, and revenge.

For years now, the term "stalking" has been used to label a pattern of persistent behaviors directed by one person towards another that is unwanted. These behaviors include escalating unwanted communications, loitering near, surveying a person's workplace or home, making multiple telephone calls, sending sexually suggestive gifts, and harassment to the extent to which a person feels threatened [2]. The vulnerability of healthcare professionals and psychologists to these forms of malicious intrusion behaviors and attacks is a heritage of the profession that cannot be whittled down [3] as they are regularly in contact with disordered, emotional, or physical struggling and lonely individuals.

In Australia for example, most health professionals, namely general practitioners, psychiatrists, gynecologists, rheumatologists, psychologists, nurses, and occupational therapists were all subjected to multiple forms of harassment [4]. Other evidence from the United State and international surveys as well as qualitative studies further suggest that one in every ten physicians will encounter patient stalking occasionally in their professional careers [5]. These harassments included repeatedly being followed or approached, physically and sexually assaulted, and being bombarded with letters and telephone calls that lasted from months to years [4]. In response to these various forms of stalking, the majority were left with no option but to change their social and work lives and to change or cease employment, while others reported varying degrees of anxiety, flashbacks, nightmares, appetite disturbances, depressed moods, and suicidal ruminations [4].

Even though the extent to which stalking can be adequately defined is a subject of heated debate, it's indeed relevant to highlight noteworthy issues pertaining to the stalking of healthcare professionals by their clients or patients. Moreover, very few review papers exist in the area of stalking healthcare professionals and psychologists. This means that the harm suffered by these victims is often overlooked and unreported. So, therefore, this paper is to remind professionals working in helping relationships that stalking is part of a constellation of unwanted behaviors that are associated with the dissatisfaction of the treatment process or termination of therapeutic relationships. More specifically to investigate the prevalence, motives, and effects of stalking healthcare professionals and psychologists.

To comprehensively locate and synthesize studies and articles that bear the particular aims and objectives of the review, we searched databases such as PubMed and Google Scholar for relevant related studies and articles. Initially, potentially relevant studies and articles were identified, followed by determining their eligibilities to be included in the study. For articles and studies deemed eligible, based on not just stalking but stalking of healthcare professionals and psychologists by their clients and patients, their findings were extracted as well 
as their literatures were reviewed. Finally, a detailed presentation and discussion of core findings were presented and interpreted using narration.

\section{Definition and Genesis of Stalking}

Stalking is a new word for an old behavior as old as man. The term apparently became a disputed social problem in the English world at the end of the $20^{\text {th }}$ century. However, Lowney and Best, [6] traced its early history back to the late 1980s when women were persistently pursuit by their ex-partners. Heckel and Roberts [7] also reported similar occurrences in the 1980s, with media stories documenting the long-standing pursuit of $\mathrm{tv}$ and screen personalities by their delusional and obsessed followers. All such behaviors at that time were defined as "obsessive following, female harassment or psychological assault [8]."

It was until 1990 when the term was first classified as a criminal offense in California. The agitation involved the murder of actress Rebecca Schaeffer by an obsessed fan who persistently pursued her for years [9]. Even though the term stalking was not explicitly used in that regard, it led to the enactment of legislation prohibiting willful harassment in the USA, Canada, United Kingdom, and across other European countries [1].

Currently what constitutes stalking is debatable. Because many behaviors normally considered as stalking (e.g., sending emails, gifts, and making telephone calls) are socially acceptable and harmless behaviors. In an attempt to answer this question, other researchers and writers believed that such behaviors only constituted stalking when it is persistent, or unwanted, especially if the victim complains of fear and distress. Regardless, studies on the stalking of healthcare professionals have continued to differ as to how many cases of repeated or persistent harassment are likely to constitute stalking. At the baseline, definitions that included two or more episodes in which a patient pursued inappropriate contact outside the treatment environment that aroused suspicion and distress were considered sufficient to constitute stalking [10]. At its extreme, healthcare professionals are expected to experience an increased incidence of intrusions, occurring over a period of two or more weeks that has caused fears and distress to be considered as stalking [11].

Furthermore, the term has also been used to describe modern times forms of close relationship, in which parties involved in such relationships have opposing goals rather than cooperative goals [12]. In such relationships, a woman is often said to want to end the relationship but finds herself unable to do so, and a man often wants to grow the relationship [12]. What has emerged from this insight is that gender interferes with stalking, including the context in which the behavior occurs. As such, women often stalk other women, whereas men often than always stalk women [13].

Unfortunately, all these ongoing ambiguities as to what constituted stalking and the emerges of gender means, the inclusion or exclusion of certain behaviors that are termed as stalking may alter the extent to which the term is used in both 
genders [14]. Moreover, based on the subjective elements in the report of unwanted communications and approaches, interest in stalking is likely to be reported out of false claims [15].

\section{Motives and Typologies}

People have long been harassed, intruded, and followed. But since the growth of the internet, these behaviors have become easier for stalkers, either as an extension of their existing activities, or a completely different means of intruding, and harassing their targets [16] [17] [18]. Most often, writers on the subject do not see any fundamental difference between proximal or physical stalking and cyberstalking [e.g. [17] [18]].

However, core elements of cyberstalking included: pursuing and collating victims details to harass, threaten and intimidate them online or offline, spamming and sending viruses, subscribing victims to services, sending e-mails, and instant messages, sending false messages with victims' details, and posting victims personal details with dubitable provocation [19] [20]. It is quite interesting as to why patients would turn to harass a professional even though the professional is guided by a core principle of taking actions that is in their interest.

In an attempt to understand why stalkers stalk, the psychological explanation of stalking turns to group stalkers into two groups, those with psychotic and nonpsychotic [1]. Most nonpsychotic stalkers chase victims out of anger, blames, obsession, revenge, denial, jealousy, and dependency [21]. In the same vein, other reasons as to why clients and patients stalk healthcare clinicians may also be centered on erotomania and hostility against the professional, largely relating to some supposed injury or dereliction.

In the case of erotomania, patients and clients perceive false love signals, with some willing to give up their already established relationship, and a failure to reciprocate this feeling leads to persistent accusations, quarrels, and vengeance [22]. Many other studies have also reported similar occurrences. For example, in McIvor, Potter, \& Davies, [10] psychiatrists accounted for clients and patients who perceived therapeutic relationships as amorous interest, as a result sending letters and gifts, and extremely eager for assurance and sexual relationships.

The same study also reported instances of hostility, anger, accusation, and legal threat due to perceived poor treatment, falsification of medical records, and poor management strategies. Precisely, clients were reported to have mounted posters denouncing the credibility of victims [10] not withstanding this insight, stalkers or perhaps stalking was further classified on the basis of stalker-victim relationship, namely: intimacy seekers, rejected stalkers, incompetent stalkers, resentful stalkers, and predators [1].

\section{Prevalence of Stalking Healthcare Professionals}

The key to the provision of healthcare and psychological services is the underlying principle of not inflicting harm to one's client. Psychologists for instance can 
find it difficult to immunize themselves against, threats, abuses, harassment, and stalking even when ethical standards allow them to disclose sensitive details regarding potentially dangerous clients [23]. Most of the time, these professionals find themselves in situations where they have no preference but to safeguard the privacy and interest of their clients, even when they cause them distress and fear [23].

Unfortunately, these professionals are very vulnerable to being victims of stalking across different motivational subgroups [1]. Studies indicate that one out of every three mental health professionals will fear for their lives at some point in their career [23]. A literature review on stalking among psychiatrists also revealed that up to $20 \%$ of psychiatrists have been stalked by their patients for a period lasting between weeks to 16 years [24]. These stalkers were male, single, and unemployed, and three out of four were reported to have psychotic and/or personality disorders.

Regardless of the fore-mentioned, the prevalence, nature, and means of stalking healthcare professionals and psychologists considerably varied across different nations and studies. In Australia and New Zealand, more than $20 \%$ of plastic surgeons reported being victims of stalking [25]. The majority of the victims were harassed with the use of written or electronic materials, threatened with a lawsuit, threatened with professional complaints, threatened with harm, and threatened with the spread of malicious rumors. In all cases, the stalkers were reported to either be angry or to have perceived the incompetence of the surgeons, therefore seeking resentment or greater intimacy.

A similar line of findings was also reported in a study among mental health nurses and physicians in New Zealand [26] and Australia [11]. However, in those studies, regardless of the disciple, women were reported to be more likely than men to have experienced stalking, and these stalkers were largely current or former clients [26]. Moreover, in Purcell, Powell, \& Mullen, [11] victims' perceptions of why they were stalked were not different from the previously reported theme of anger, resentment, and intimacy.

Other anecdotal evidence such as a study in Italy to test whether stalking was a clearly defined problem for mental health professionals, the prevalence of stalking among healthcare professionals were reported to be between $6 \%-13 \%$ [27] [28]. In those instances, too, the victims were psychiatric nurses, psychiatrists, and psychologists and the stalkers were clients under their care. Reasons as to why those stalkers stalk were the desirers for more intimate relationships, and a sense of revenge, while the most common method adopted by the stalkers included intrusive approaches, telephone calls, maintaining surveillance, sending letters, violating properties, and spreading gossips.

Healthcare professionals, particularly medical care professionals have been overrepresented in many past studies, yet the prevalence rate in this population wasn't largely known, owing to differences in definition and silence of victims. It is until these past years that studies on prevalence started to revealed interest figures and findings. The English-speaking world has also reported overwhelm- 
ing evidence of clinicians and psychologists been stalked by clients and patients.

One of such studies was a collective case-study approach by Miedema, Easley, Fortin, Hamilton, \& Tatemichi [29] in Canada to examine the working environment of family physicians. Later in the study, intimidation, harassment, and abuses encountered in the workplace emerged as the theme of the study. Those forms of stalking ranged from minor (disrespect, verbal threats from patients, their families, and colleagues) to severe (physical threats and attacks). Furthermore, among American psychologists, roughly $10 \%$ of the sample studied were found to be past victims of serious stalking by their clients [30].

However, it is strange to discover that in no instances were the psychologists physically attacked by the stalking client [30]. The absence of physical attacks in part may be due to the fact that stalking is considered a crime in the US. Psychologists who were stalked defined their stalkers as having mood disorders, personality disorders, and stress-related disorders, caused by emotional, physical, and sexual abuse.

Another study in the United Kingdom indicates that $50 \%$ of mental health nurses in a survey had been stalked in the past, with the majority of victims being female stalked by men [31]. This high reported prevalence was coherent to a study by Sandberg, McNiel, \& Binder [32] which also found a prevalence of 53\% among affiliated staff members of university-based psychiatric inpatient units. But in Sandberg, McNiel, \& Binder, [32] victims were reported to have experienced more serious forms of stalking such as obsessional following that threatened the safety of the victims.

\section{Physical and Emotional Effect of Stalking}

Violence has always occurred in $25 \%-35 \%$ of stalking cases [33] [34]. Stalking has also other severe aftereffects for the victim. In general, analysis of impact of stalking for instance indicates that victims often experience sleeping disturbances, anxiety, fear, and anger [35] [36].

Overall, healthcare professionals who are victims of stalking encounter anxiety, distress, powerlessness, [32] sleep disorders, weight problems, headaches, and panic attacks [31] [37]. Other effects of stalking of healthcare professionals and psychologists are the negative effects it has on their functionality [28]. For example, oppression and harassment are likely to increase the instinct of insecurity, which will cause a canter approach of emotional withdrawal from any helping relationship.

Victims who are also exposed to prolonged episodes of stalking may also relocate, take time off or, at the extreme even change their work [38]. While others may turn to the use of substances to cope with the high levels of anxiety and raising thoughts [39].

\section{Conclusions}

From the review, it is evidenced that stalking of healthcare professionals and 
psychologists is a frequent occurrence and it equally does great harm to the victims. In addition to that, reports suggest that healthcare professionals and psychologists are yet to come to terms on the best possible response to undertake when stalked. What is also clear is that effective coping strategies are lacking as to how these professionals can effectively deal with clients and patients stalking.

Therefore, we strongly believe that further studies on the topic still have a lot to explore as healthcare professionals and psychologists are always stalked by their clients, however denial and minimization were the common reaction used to avert these malicious behaviors. We also believe that the stalking of healthcare professionals can be well understood in a model that examines the relationship between the stalker and the victim. Such an approach could provide detailed differences between normal socially acceptable behaviors that could be misunderstood as stalking and malicious threatening behaviors.

Lastly, stalking is a challenge that professionals in helping relationships are more likely to face from time to time, therefore making it important for trainees to be educated on how to manage its effects, for little is known on its management aside from the use of judicial means.

\section{Conflicts of Interest}

The authors declare no conflicts of interest regarding the publication of this paper.

\section{References}

[1] Mullen, P.E., Pathé, M. and Purcell, R. (2000) Stalkers and Their Victims. Cambridge University Press, Cambridge. https://doi.org/10.1017/CBO9781139106863

[2] Abrams, K.M. and Robinson, G.E. (2011) Stalking by Patients: Doctors' Experiences in a Canadian Urban Area. The Journal of Nervous and Mental Disease, 199, 738-743. https://doi.org/10.1097/NMD.0b013e31822fc7aa

[3] Purcell, R., Pathe, M. and Mullen, P.E. (2005) Association between Stalking Victimisation and Psychiatric Morbidity in a Random Community Sample. The British Journal of Psychiatry, 187, 416-420. https://doi.org/10.1192/bjp.187.5.416

[4] Pathe, M. and Mullen, P.E. (1997) The Impact of Stalkers on Their Victims. The British Journal of Psychiatry, 170, 12-17. https://doi.org/10.1192/bjp.170.1.12

[5] Butler, D.J. and Duenk, L. (2013) Physicians Stalked by Patients: Implications for Family Medicine Resident Education and Practice. Annals of Behavioral Science and Medical Education, 19, 19-23. https://doi.org/10.1007/BF03355233

[6] Lowney, K.S. and Best, J. (1995) Stalking Strangers and Lovers: Changing Media Typifications of a New Crime Problem. Images of Issues: Typifying Contemporary Social Problems, 2, 33-57. https://doi.org/10.4324/9781351310284-5

[7] Heckels, V. and Roberts, K. (2010) Stalking and Harassment. In: Handbook on Crime, Willan Publishing, Cullompton, 366-379.

[8] Jason, L.A., Reichler, A., Easton, J., Neal, A. and Wilson, M. (1984) Female Harassment after Ending a Relationship: A Preliminary Study. Alternative Lifestyles, 6, 259-269. https://doi.org/10.1007/BF01083054

[9] Anderson, S.C. (1993) Anti-Stalking Laws. Law and Psychological Review, 17, 
171-185.

[10] Mclvor, R.J., Potter, L. and Davies, L. (2008) Stalking Behaviour by Patients towards Psychiatrists in a Large Mental Health Organization. International Journal of Social Psychiatry, 54, 350-357. https://doi.org/10.1177/0020764008090690

[11] Purcell, R., Powell, M.B. and Mullen, P.E. (2005) Clients Who Stalk Psychologists: Prevalence, Methods, and Motives. Professional Psychology: Research and Practice, 36, 537-543. https://doi.org/10.1037/0735-7028.36.5.537

[12] Spitzberg, B.H. and Cupach, W.R. (2002) The Inappropriateness of Relational Intrusion. In: Goodwin, R. and Cramer, D., Eds., Inappropriate Relationships: The Unconventional, the Disapproved, and the Forbidden, Psychology Press, Hove, 191-219.

[13] Purcell, R., Pathé, M. and Mullen, P.E. (2001) A Study of Women Who Stalk. American Journal of Psychiatry, 158, 2056-2060. https://doi.org/10.1176/appi.ajp.158.12.2056

[14] Davis, K.E., Swan, S.C. and Gambone, L.J. (2012) Why Doesn't He Just Leave Me Alone? Persistent Pursuit: A Critical Review of Theories and Evidence. Sex Roles, 66, 328-339. https://doi.org/10.1007/s11199-010-9882-3

[15] Pathe, M., Mullen, P.E. and Purcell, R. (1999) Stalking: False Claims of Victimisation. British Journal of Psychiatry, 174, 170-172. https://doi.org/10.1192/bjp.174.2.170

[16] Get Safe Online (2021) Cyberstalking. Get Safe Online Free Expert Advice. https://www.getsafeonline.org/protecting-yourself/cyberstalking

[17] Spitzberg, B.H. and Hoobler, G. (2002) Cyberstalking and the Technologies of Interpersonal Terrorism. New Media \& Society, 4, 71-92. https://doi.org/10.1177/14614440222226271

[18] Sheridan, L.P. and Grant, T. (2007) Is Cyberstalking Different? Psychology, Crime, and Law, 13, 627-640. https://doi.org/10.1080/10683160701340528

[19] Finn, J. (2004) A Survey of Online Harassment at a University Campus. Journal of Interpersonal Violence, 19, 468-483. https://doi.org/10.1177/0886260503262083

[20] McGrath, M.G. and Casey, E. (2002) Forensic Psychiatry and the Internet: Practical Perspectives on Sexual Predators and Obsessional Harassers in Cyberspace. Journal of the American Academy of Psychiatry and the Law, 30, 81-94.

[21] Kienlen, K.K., Birmingham, D.L., Solberg, K.B., O’Regan, J.T. and Meloy, J.R. (1997) A Comparative Study of Psychotic and Nonpsychotic Stalking. Journal of the American Academy of Psychiatry and the Law, 25, 317-334.

[22] Frías, Á., Palma, C., Farriols, N. and Martínez, B. (2015) Sexual Feelings toward the Therapist among Patients with Borderline Personality Disorder: A Case of Erotomanic Delusional Disorder. Archives of Sexual Behavior, 44, 3-4. https://doi.org/10.1007/s10508-014-0433-9

[23] Arthur, G.L., Brende, J.O. and Quiroz, S.E. (2003) Violence: Incidence and Frequency of Physical and Psychological Assaults Affecting Mental Health Providers in Georgia. The Journal of General Psychology, 130, 22-45. https://doi.org/10.1080/00221300309601272

[24] Paraschakis, A. and Konstantinidou, D. (2012) P-664-Stalking of Psychiatrists by Their Patients: An Unsettling Reality. European Psychiatry, 27, 1. https://doi.org/10.1016/S0924-9338(12)74831-9

[25] Allnutt, S., Samuels, A. and Taylor, G. (2009) The Harassment and Stalking of Plastic Surgeons by Their Patients in Australasia. ANZ Journal of Surgery, 79, 533-536. 
https://doi.org/10.1111/j.1445-2197.2009.04984.x

[26] Hughes, F., Thom, K. and Dixon, R. (2007) Nature and Prevalence of Stalking among New Zealand Mental Health Clinicians. Journal of Psychosocial Nursing and Mental Health Services, 45, 32-39. https://doi.org/10.3928/02793695-20070401-08

[27] Galeazzi, G.M., Elkins, K. and Curci, P. (2005) Emergency Psychiatry: The Stalking of Mental Health Professionals by Patients. Psychiatric Services, 56, 137-138. https://doi.org/10.1176/appi.ps.56.2.137

[28] Mclvor, R.J. and Petch, E. (2006) Stalking of Mental Health Professionals: An Underrecognised Problem. The British Journal of Psychiatry, 188, 403-404. https://doi.org/10.1192/bjp.bp.105.018523

[29] Miedema, B., Easley, J., Fortin, P., Hamilton, R. and Tatemichi, S. (2009) Disrespect, Harassment, and Abuse: All in a Day's Work for Family Physicians. Canadian Family Physician, 55, 279-285.

[30] Gentile, S.R., Asamen, J.K., Harmell, P.H. and Weathers, R. (2002) The Stalking of Psychologists by Their Clients. Professional Psychology: Research and Practice, 33, 490. https://doi.org/10.1037/0735-7028.33.5.490

[31] Ashmore, R., Jones, J., Jackson, A. and Smoyak, S. (2006) A Survey of Mental Health Nurses' Experiences of Stalking. Journal of Psychiatric and Mental Health Nursing, 13, 562-569. https://doi.org/10.1111/j.1365-2850.2006.00981.x

[32] Sandberg, D.A., McNiel, D.E. and Binder, R.L. (2002) Stalking, Threatening, and Harassing Behavior by Psychiatric Patients toward Clinicians. Journal of the American Academy of Psychiatry and the Law Online, 30, 221-229.

[33] Meloy, J.R. (2003) When Stalkers Become Violent: The Threat to Public Figures and Private Lives. Psychiatric Annals, 33, 659-665.

https://doi.org/10.3928/0048-5713-20031001-09

[34] Blaauw, E., Winkel, F.W., Arensman, E., Sheridan, L. and Freeve, A. (2002) The Toll of Stalking: The Relationship between Features of Stalking and Psychopathology of Victims. Journal of Interpersonal Violence, 17, 50-63. https://doi.org/10.1177/0886260502017001004

[35] Cupach, W.R. and Spitzberg, B.H. (2004) The Dark Side of Relationship Pursuit: From Attraction to Obsession and Stalking. Lawrence Erlbaum, Mahwah. https://doi.org/10.4324/9781410609908

[36] Spitzberg, B.H. and Cupach, W.R. (2007) The State of the Art of Stalking: Taking Stock of the Emerging Literature. Aggression and Violent Behavior, 12, 64-86. https://doi.org/10.1016/j.avb.2006.05.001

[37] Acquadro Maran, D., Varetto, A. and Zedda, M. (2014) Italian Nurses' Experience of Stalking: A Questionnaire Survey. Violence and Victims, 29, 109-121. https://doi.org/10.1891/0886-6708.VV-D-12-00078

[38] Purcell, R., Pathe, M. and Mullen, P. (2004) When Do Repeated Intrusions Become Stalking? Journal of Forensic Psychiatry \& Psychology, 15, 571-583. https://doi.org/10.1080/14789940412331313368

[39] Pathé, M. (2002) Surviving Stalking. Cambridge University Press, Cambridge. https://doi.org/10.1017/CBO9780511544200 